\title{
Stimulation of the lateral geniculate, superior colliculus, or visual cortex is sufficient for eyeblink conditioning in rats
}

\author{
Hunter E. Halverson, Erin M. Hubbard, and John H. Freeman ${ }^{1}$ \\ Department of Psychology, University of lowa, lowa City, lowa 52242, USA
}

\begin{abstract}
The role of the cerebellum in eyeblink conditioning is well established. Less work has been done to identify the necessary conditioned stimulus (CS) pathways that project sensory information to the cerebellum. A possible visual CS pathway has been hypothesized that consists of parallel inputs to the pontine nuclei from the lateral geniculate nucleus (LGN), superior colliculus (SC), pretectal nuclei, and visual cortex (VCTX) as reported by Koutalidis and colleagues in an earlier paper. The following experiments examined whether electrical stimulation of neural structures in the putative visual CS pathway can serve as a sufficient CS for eyeblink conditioning in rats. Unilateral stimulation of the ventral LGN (Experiment 1), SC (Experiment 2), or VCTX (Experiment 3) was used as a CS paired with a periorbital shock unconditioned stimulus. Stimulation was delivered to the hemisphere contralateral to the conditioned eye. Rats in all experiments were given five 100-trial sessions of paired or unpaired eyeblink conditioning with the stimulation CS followed by three paired sessions with a light CS. Stimulation of each visual area when paired with the unconditioned stimulus supported acquisition of eyeblink conditioned responses (CRs) and substantial savings when switched to a light CS. The results provide evidence for a unilateral parallel visual CS pathway for eyeblink conditioning that includes the LGN, SC, and VCTX inputs to the pontine nuclei.
\end{abstract}

Pavlovian eyeblink (eyelid closure and nictitating membrane movement) conditioning is established by pairing a conditioned stimulus (CS), usually a tone or light, with an unconditioned stimulus (US) that elicits the eyeblink reflex. The eyeblink conditioned response (CR) emerges over the course of paired training, occurs during the CS, and precedes the US (Gormezano et al. 1962; Schneiderman et al. 1962). Neurobiological investigations of Pavlovian eyeblink conditioning have primarily focused on the cerebellum, which is the site of memory formation and storage (Thompson 2005). The anterior interpositus nucleus is necessary for acquisition and retention of the eyeblink CR (Lavond et al. 1985; Krupa and Thompson 1997; Freeman Jr. et al. 2005; Thompson 2005; Ohyama et al. 2006). Lobule HVI and the anterior lobe of the cerebellar cortex (lobules I-V) contribute to acquisition, retention, and timing of the CR (McCormick and Thompson 1984; Perrett et al. 1993; Perrett and Mauk 1995; Attwell et al. 1999, 2001; Medina et al. 2000; Nolan and Freeman Jr. 2005; Nolan and Freeman 2006). The brainstem nuclei that comprise the proximal ends of the CS and US input pathways to the cerebellum have also been identified.

The pontine nuclei $(\mathrm{PN})$ and inferior olive $(\mathrm{IO})$ receive $\mathrm{CS}$ and US information, respectively, and are the primary sensory relays into the interpositus nucleus and cerebellar cortex (Thompson 2005). Conditioned stimulus information converges in the PN, which receives projections from lower brainstem, thalamus, and cerebral cortex (Glickstein et al. 1980; Brodal 1981; Schmahmann and Pandya 1989; Knowlton et al. 1993; Campolattaro et al. 2007). The lateral pontine nuclei (LPN) are the sources of auditory CS information projected into the cerebellum. Lesions of the LPN block CR retention to a tone CS, but have no effect on CRs to a light CS (Steinmetz et al. 1987). Thus, CS inputs from different

'Corresponding author.

E-mail john-freeman@uiowa.edu; fax (319) 335-0191.

Article is online at http://www.learnmem.org/cgi/doi/10.1101/lm.1340909. sensory modalities may be segregated at the level of the PN. Neurons in the PN project CS information into the contralateral cerebellum via mossy fibers in the middle cerebellar peduncle that synapse primarily on granule cells in the cerebellar cortex and on neurons in the deep nuclei (Bloedel and Courville 1981; Brodal 1981; Steinmetz and Sengelaub 1992). Stimulation of the PN acts as a supernormal CS supporting faster CR acquisition than conditioning with peripheral stimuli (Steinmetz et al. 1986, 1989; Rosen et al. 1989; Steinmetz 1990; Tracy et al. 1998; Freeman Jr. and Rabinak 2004). The primary focus of these experiments was to investigate the most proximal components of the CS pathway in eyeblink conditioning. There has been less emphasis on identifying the critical CS pathways that project information to the PN.

Recent studies using lesions, inactivation, stimulation, and neural tract tracing have provided evidence that the auditory CS pathway that is necessary for acquisition and retention of eyeblink conditioning is comprised of converging inputs to the medial auditory thalamic nuclei (MATN), and a direct ipsilateral projection from the MATN to the PN (Halverson and Freeman 2006; Campolattaro et al. 2007; Freeman et al. 2007; Halverson et al. 2008). Unilateral lesions of the MATN, contralateral to the conditioned eye, block acquisition of eyeblink CRs to a tone CS but have no effect on conditioning with a light CS (Halverson and Freeman 2006). Inactivation of the MATN with muscimol blocks acquisition and retention of CRs to an auditory CS, and decreases metabolic activity in the PN (Halverson et al. 2008). The MATN has a direct projection to the PN and stimulation of the MATN supports rapid CR acquisition (Campolattaro et al. 2007). Our current model of the auditory CS pathway consists of converging inputs to the MATN, and direct unilateral thalamic input to the PN (Halverson et al. 2008).

Less work has been done to identify the visual CS pathway necessary for eyeblink conditioning. A possible parallel visual CS pathway has been hypothesized, which includes parallel inputs to different areas of the PN from the lateral geniculate nucleus (LGN), 
superior colliculus (SC), visual cortex (VCTX), and pretectal nuclei (Koutalidis et al. 1988). In the Koutalidis et al. study, lesions of the LGN, SC, VCTX, or pretectal nuclei alone had only a partial effect on CR acquisition with a light CS. Lesions of any two of these structures together produced a more severe impairment on acquisition and combined lesions of all of these areas completely blocked CR acquisition to a light CS (Koutalidis et al. 1988). Each visual area investigated in the Koutalidis et al. study has a direct projection to the PN that could be important for eyeblink conditioning. The ventral LGN projects to the medial, and to a lesser extent, the lateral PN (Graybiel 1974; Wells et al. 1989). The superficial, intermediate, and deep layers of SC send projections to both the dorsomedial and dorsolateral PN (Redgrave et al. 1987; Wells et al. 1989). The VCTX has a direct projection to the rostral and lateral portions of the PN (Glickstein et al. 1972; Baker et al. 1976; Mower et al. 1980; Wells et al. 1989). The pretectal nuclei also have a direct projection to both the medial and lateral PN (Weber and Harting 1980; Wells et al. 1989). However, stimulation of the anterior pretectal nucleus is not an effective CS for eyeblink conditioning (Campolattaro et al. 2007). The failure to establish conditioning with stimulation of the anterior pretectal nucleus as a CS suggests that there may be differences in the efficacy of the various visual inputs to the PN for cerebellar learning. The following experiments investigated the sufficiency of stimulation of the LGN, SC, or primary VCTX as a CS for eyeblink conditioning in rats.

\section{Results}

\section{Experiment 1: Lateral geniculate stimulation}

Experiment 1 examined whether stimulation of the ventral division of the LGN is a sufficient CS to support associative eyeblink conditioning. The dorsal and ventral nuclei of the LGN receive a direct projection from the retina (Watanabe et al. 2001; Major et al. 2003; Matteau et al. 2003). The ventral LGN (parvocellular) also receives projections from the $\mathrm{PN}$, deep layers of the SC, periaqueductal gray (Kolmac and Mitrofanis 2000), and a feedback projection from the deep cerebellar nuclei (Zimny et al. 1986). The dorsal LGN primarily projects to the visual cortex (Kawano 1998), while the ventral LGN has an exclusively ipsilateral projection to both medial and lateral PN (Graybiel 1974; Ribak and Peters 1975; Wells et al. 1989; Moore et al. 2000). The anatomical connections of the LGN, primarily the ventral LGN, make it a likely candidate to support visual eyeblink conditioning. The role of the ventral LGN-PN projection in eyeblink conditioning has not been investigated separately from the dorsal LGN-VCTX-PN projection.

In Experiment 1, rats were first fitted with a bipolar stimulating electrode in the ventral LGN contralateral to the conditioned eye, and then given five 100-trial sessions of paired $(n=11)$ or unpaired $(n=11)$ delay eyeblink conditioning with LGN stimulation as the CS and a periorbital shock US in phase 1 of training. In phase 2 , all rats were given three 100-trial sessions of paired training with a light CS to examine savings.

\section{Electrode placement}

The electrodes delivering stimulation in both the paired and unpaired groups during phase 1 were all located in the ventral division of the LGN (Fig. 1A).

\section{Eyeblink conditioning}

There was an increase in CR percentage in the paired group across sessions 1-5 in phase 1 , which was due to associative learning, as the unpaired group did not show an increase in responding across sessions. Rats in the paired group showed more CRs during all sessions (sessions 1-5) (Fig. 1B) than rats in the unpaired group.
A

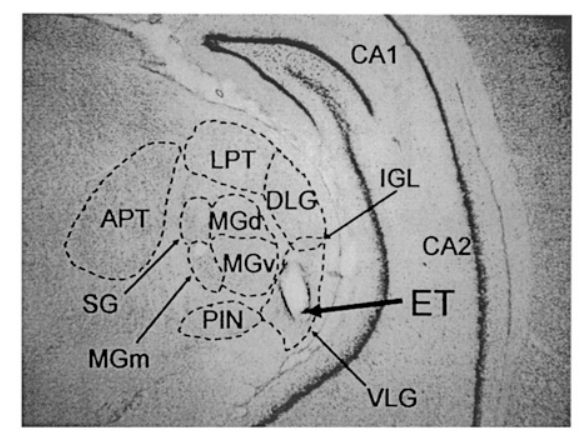

B

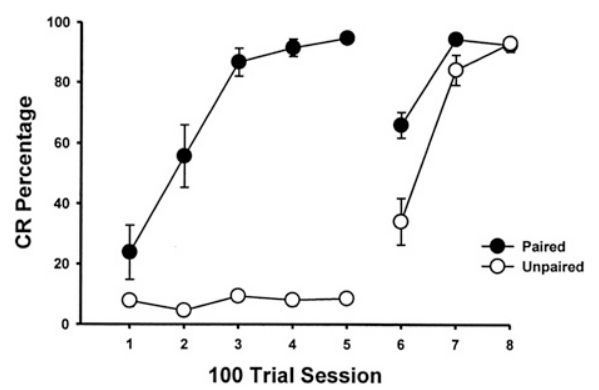

Figure 1. (A) Example of a stimulation electrode placement in the ventral lateral geniculate nucleus (LGN). (APT) Anterior pretectal nucleus; (DLG) dorsal lateral geniculate; (ET) electrode tip; (LPT) lateral posterior thalamus; (MGd) dorsal division of the medial geniculate; (MGm) medial division of the medial geniculate; (MGv) ventral division of the medial geniculate; (PIN) posterior intralaminar nucleus; (SG) suprageniculate; (VLG) ventral lateral geniculate. (B) Mean \pm SE conditioned response (CR) percentage for rats given paired or unpaired training with an LGN stimulation CS (sessions 1-5) followed by paired training with a light CS (sessions 6-8). Rats receiving paired training with the LGN stimulation CS showed an increase in CR percentage over the course of training and savings to the light CS on session 6.

Both the paired and unpaired groups from phase 1 of training received paired training with a light CS in phase 2 , and showed an increase in CR percentage across sessions 6-8 (Fig. 1B). Rats in the paired group showed more CRs on session 6 than rats in the unpaired group (Fig. 1B). Rats in the paired group thus showed substantial savings when switched from the LGN stimulation CS to a light CS (session 6) (Fig. 1B).

A repeated measures ANOVA on the CR percentage data for the paired and unpaired groups for the first phase (sessions 1-5) yielded an interaction of the session and group factors $\left(F_{(4,80)}=\right.$ 27.03, $P<0.0001)$. Post-hoc tests indicated that rats in the paired group showed more CRs than rats in the unpaired group during sessions $2-5$ ( $P<0.05$; Fig. 1B). The magnitude of the CR difference between the groups increased across sessions in phase 1 . Another repeated measures ANOVA on the CR percentage data for the paired and unpaired groups for the second phase (sessions 6-8) in which both groups received paired training with a light CS yielded an interaction of the session and group factors $\left(F_{(2,40)}=10.53, P<\right.$ 0.001). Post-hoc tests indicated that rats in the paired group showed more CRs on the first session of phase 2 (session 6) than rats in the unpaired group $(P<0.05$; Fig. $1 \mathrm{~B})$.

Analysis of CR amplitude, CR onset, and peak latency was done on the paired group data only because the unpaired group did not produce a sufficient number of responses for statistical analysis. Data for these measures were taken from CS-alone trials to eliminate contamination from the UR. Data from sessions 1 and 2 were pooled because some of the rats did not produce any CRs on CS-alone trials during session 1. An ANOVA of the CR amplitude data yielded a main effect of the session factor $\left(F_{(3,40)}=9.15, P<\right.$ 
0.001). Post-hoc tests indicated that CR amplitude was higher on sessions 3-5 relative to amplitude on sessions $1-2$. ANOVAs of the onset and peak latency data both found a main effect of the session variable that reflected decreases from sessions $1-2$ to sessions $3-5\left(F_{(3,40)}=5.58, P<0.003\right.$ for onset and $F_{(3,40)}=3.84$, $P<0.02$ for peak). The increase in amplitude and decreases in onset and peak latency across the initial conditioning sessions are consistent with previous reports of CR performance using a peripheral CS (Nolan and Freeman 2006).

\section{Experiment 2: Superior colliculus stimulation}

Experiment 2 examined whether unilateral stimulation of the SC can support acquisition of eyeblink conditioning. The SC includes superficial, intermediate, and deep layers, and each layer group receives a direct retinal projection (Watanabe et al. 2001; Major et al. 2003; Matteau et al. 2003; Fleming et al. 2006; Prichard et al. 2007). Like the ventral LGN, the SC receives a projection from the cerebellum (interpositus nucleus) (Gonzalo-Ruiz and Leichnetz 1987). The superficial, intermediate, and deep layers of SC send direct projections to the dorsolateral and dorsomedial pontine nucleus (Kawamura and Brodal 1973; Redgrave et al. 1987; Wells et al. 1989). Lesions of the SC in the Koutalidis et al. (1988) study produced a partial impairment in CR acquisition, demonstrating that the SC is not essential for eyeblink conditioning with a visual CS but probably contributes to acquisition.

In Experiment 2, rats were first implanted with a bipolar stimulating electrode in the SC contralateral to the conditioned eye, and then given the same training sequence as in Experiment 1 with paired $(n=12)$ or unpaired $(n=9)$ presentations of a SC stimulation CS and the US, followed by paired conditioning with a light CS.

\section{Electrode placement}

The electrodes delivering stimulation in both the paired and unpaired groups during phase 1 were located in the superficial gray layer $(n=8)$, optic layer $(n=6)$, or intermediate gray layer $(n=$ 7; Fig. 2A). CR acquisition in the paired group during phase 1 was not influenced by electrode placement.

\section{Eyeblink conditioning}

An increase in CR percentage was observed in the paired group across sessions in phase 1, but rats in the unpaired group did not show an increase in responding across sessions (Fig. 2B). A repeated measures ANOVA on the CR percentage data for the paired and unpaired groups for the first phase (sessions 1-5) yielded an interaction of the session and group factors $\left(F_{(4,76)}=16.88, P<\right.$ $0.0001)$. Post-hoc tests indicated that rats in the paired group showed more CRs than rats in the unpaired group during sessions 3-5 $(P<0.05$; Fig. 2B). In addition, the magnitude of the CR difference between the groups increased across sessions 2-5 in phase 1. An ANOVA on CR percentage data for the paired groups separated by electrode placement found no significant differences between groups across sessions $1-5\left(F_{(8,28)}=0.87\right)$.

The paired and unpaired groups showed an increase in CR percentage across sessions $6-8$ with the light CS (Fig. 2B). A repeated measures ANOVA on the CR percentage data for the paired and unpaired groups for the second phase (sessions 6-8) yielded an interaction of the session and group factors $\left(F_{(2,38)}=\right.$ $12.81, P<0.001)$. Post-hoc tests indicated that rats in the paired group showed more CRs on the first session of phase 2 (session 6) than rats in the unpaired group $(P<0.05$; Fig. 2B). Rats in the paired group, therefore, showed substantial savings when switched from the SC stimulation CS to a light CS (session 6) (Fig. 2B).

CR amplitude increased across training sessions during phase $1\left(F_{(3,39)}=3.25, P<0.04\right)$. The onset and peak latencies decreased
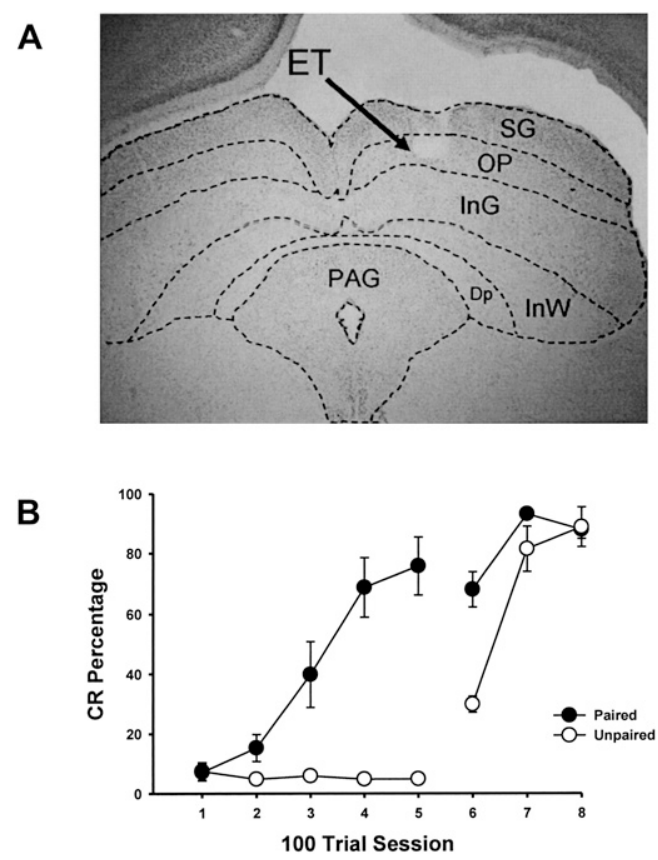

Figure 2. $(A)$ Example of a stimulation electrode placement in the (SC) superior colliculus. (Dp) Deep layer of SC; $(\operatorname{InG})$ intermediate gray layer of SC; (InW) intermediate white layer of SC; (OP) optic layer of SC; (PAG) periaqueductal gray; (SG) superficial gray layer of SC. (B) Mean \pm SE conditioned response $(C R)$ percentage for rats given paired or unpaired training with an SC stimulation CS (sessions 1-5) followed by paired training with a light CS (sessions 6-8). Rats receiving paired training with the SC stimulation CS showed an increase in CR percentage over the course of training, and savings to the light CS on session 6.

from sessions $1-2$ to sessions $3-5\left(F_{(3,39)}=4.18, P<0.02\right.$ for onset and $F_{(3,39)}=4.85, P<0.006$ for peak). As in Experiment 1 , the pattern of CR performance across sessions was consistent with eyeblink conditioning using a peripheral CS.

\section{Experiment 3: Visual cortex stimulation}

Experiment 3 examined the sufficiency of unilateral stimulation of the primary VCTX as a CS for acquisition of eyeblink conditioning. Layer IV of the primary VCTX receives direct projections from the dorsal LGN and the retina (Lashley 1934; Alonso et al. 2001). The upper portion of the visual field is represented caudally in the rat VCTX (Espinoza 1983). Stimulation of the caudal VCTX was used in Experiment 3 to more closely approximate the light CS, which was presented from a bulb near the top of the conditioning chamber used in the second phase of training. The VCTX also sends a direct ipsilateral projection to the rostral and lateral portions of the pontine nuclei (Baker et al. 1976; Mower et al. 1980; Wells et al. 1989). Converging visual input to VCTX from the thalamus and retina combined with the direct cortical projection to the PN made it likely that stimulation of the VCTX would support eyeblink conditioning.

In Experiment 3, rats were initially fitted with a bipolar stimulating electrode in the VCTX contralateral to the conditioned eye, and given the same training sequence as Experiments 1 and 2 with paired $(n=10)$ or unpaired $(n=9)$ presentations of a VCTX stimulation CS and the US, followed by paired conditioning with a light CS.

\section{Electrode placement}

The electrodes delivering stimulation in both the paired and unpaired groups during phase 1 were located in layers I-III $(n=$ $5)$, IV $(n=6)$, and V-VI $(n=8)$ of the primary visual cortex (Fig. 3A). 
A

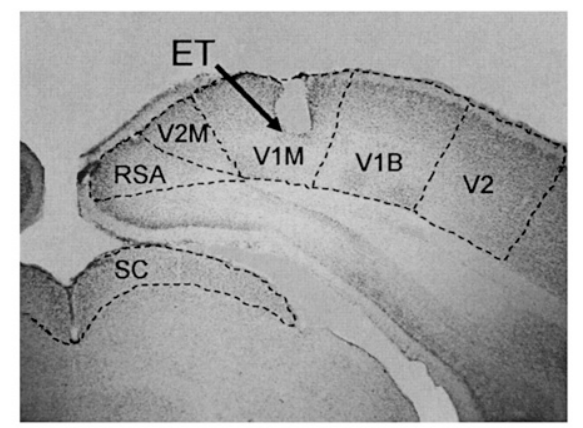

B

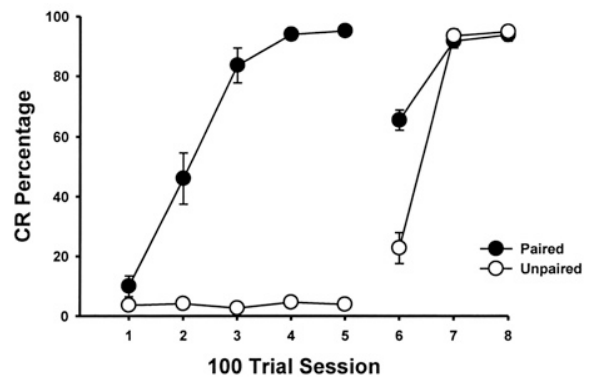

Figure 3. Example of a stimulation electrode placement in the visual cortex. (RSA) Retrosplenial agranular cortex; (SC) superior colliculus; (V1B) binocular primary visual cortex; (V1M) monocular primary visual cortex; (V2) secondary visual cortex; (V2M) medial secondary visual cortex. (B) Mean $\pm \mathrm{SE}$ conditioned response (CR) percentage for rats given paired or unpaired training with a VCTX stimulation CS (sessions 15) followed by paired training with a light CS (sessions 6-8). Rats receiving paired training with the VCTX stimulation CS showed an increase in CR percentage over the course of training and savings to the light CS on session 6.

CR acquisition rate for the paired group during phase 1 was not influenced by the location of the electrode.

\section{Eyeblink conditioning}

The paired group showed an increase in CR percentage across sessions in phase 1 , whereas the unpaired group showed a consistently low percentage of CRs across sessions (Fig. 3B). A repeated measures ANOVA on the CR percentage data for the paired and unpaired groups for the first phase (sessions 1-5) yielded an interaction of the session and group factors $\left(F_{(4,68)}=68.97, P<\right.$ 0.0001). Post-hoc tests indicated that rats in the paired group showed more CRs than rats in the unpaired group during sessions 2-5 $(P<0.05$; Fig. 3B). A repeated measures ANOVA on CR percentage data for the paired groups separated by electrode placement found no significant differences between groups across sessions $1-5\left(F_{(8,28)}=0.23\right)$.

During training with the light CS in phase 2, both the paired and unpaired groups showed an increase in CR percentage across sessions 6-8 (Fig. 3B). The paired group showed more CRs on the first session of light training (session 6) than the unpaired group (Fig. 3B). A repeated measures ANOVA on the CR percentage data for phase 2 (sessions 6-8) revealed an interaction of the session and group factors $\left(F_{(2,34)}=49.25, P<0.0001\right)$. Post-hoc tests indicated that rats in the paired group showed more CRs on the first session of phase 2 (session 6) than rats in the unpaired group $(P<0.05$; Fig. 3B).

As in Experiments 1 and 2, CR amplitude increased across sessions $\left(F_{(3,36)}=5.66, P<0.003\right)$. Onset and peak latencies of the CR decreased across sessions $\left(F_{(3,36)}=5.90, P<0.002\right.$ for onset and $F_{(3,36)}=4.28, P<0.01$ for peak $)$.

\section{Between-area comparisons}

Stimulation of the various structures in the putative visual CS pathway in Experiments 1-3 supported acquisition of eyeblink conditioning and savings when rats were switched to a light CS. Differences in CR acquisition and subsequent savings between areas in the visual CS pathway may indicate differential involvement in learning between areas. LGN and VCTX stimulation supported faster acquisition and a higher CR asymptote than stimulation of the SC. However, stimulation of all three areas supported a similar level of savings to the light CS.

A repeated measures ANOVA on the CR percentage for all groups in phase 1 revealed an interaction of the group and session factors $\left(F_{(8,120)}=2.50, P<0.05\right)$. Post-hoc tests indicated that rats receiving SC stimulation produced fewer CRs on sessions 2,3 , and 4 than rats in both the LGN and VCTX groups $(P<0.05)$. A repeated measures ANOVA on the CR percentage for all paired groups in phase 2 revealed a main effect of session $\left(F_{(2,60)}=66.47\right.$, $P<0.0001)$ but no group by session interaction. Post-hoc tests indicated that rats in all groups showed fewer CRs on the first session of phase 2 (session 6 ) than on sessions 7 and $8(P<0.05)$. Rats in each paired group showed more CRs on session 6 than rats in each unpaired group $(P<0.05)$. The absence of differences

A

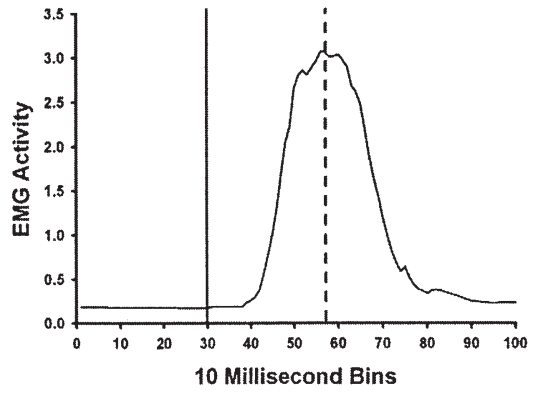

B
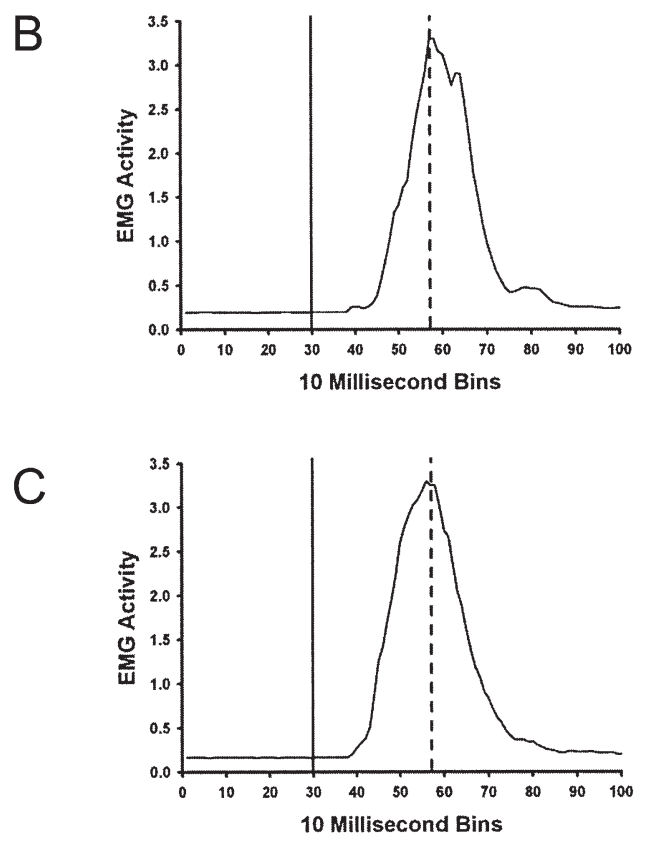

Figure 4. Averaged eyelid EMG activity on stimulation CS-alone trials for the $(A)$ LGN group, $(B)$ SC group, and (C) VCTX group on session 5. CS onset is indicated by the black bar, $300 \mathrm{msec}$, peak amplitude for all three groups occurred around US onset (dashed line). 
between the paired groups on sessions 5 and 6 indicates the transfer to the light CS was equivalent for the three stimulation sites.

Different measures of CR performance during the CS-alone trials in each of the paired groups (LGN, SC, and VCTX) during phase 1 were investigated for possible differences between areas (Fig. 4). A repeated measures ANOVA of the CR amplitude data yielded a group by session interaction $\left(F_{(3,78)}=2.66, P<0.022\right)$. Post-hoc tests indicated that CR amplitude for the LGN and VCTX groups was higher than the SC group during sessions 1-2. There was a main effect of the session variable for onset and peak latency $\left(F_{(3,78)}=16.13, P<0.001\right.$ and $F_{(3,78)}=2.04, P<0.045$, respectively $)$, but no group effects.

\section{Discussion}

Unilateral electrical stimulation of the LGN, SC, or VCTX as a CS was sufficient for acquisition of eyeblink CRs in rats. Rats receiving stimulation of the LGN or VCTX acquired CRs more rapidly than rats receiving SC stimulation. Unpaired presentations of the stimulation CS and shock US did not produce an increase in eyeblink CRs over $5 \mathrm{~d}$ of training, indicating that CRs observed in the paired groups were due to associative learning. There were no between-area differences in CR onset or peak latency. All of the paired stimulation groups showed substantial savings on the first session of phase 2 training (session 6) when the CS was switched from stimulation to a light.

A previous study using rabbits showed that combined bilateral lesions of the LGN, SC, and pretectal nuclei blocked acquisition of nictitating membrane conditioning with a light CS (Koutalidis et al. 1988). The Koutalidis et al. study did not examine the effects of unilateral lesions, so it is not clear whether visual input from both hemispheres to the $\mathrm{PN}$ is necessary for conditioning of a particular eye. However, unilateral stimulation of the LGN, SC, or VCTX in the hemisphere contralateral to the conditioned eye was sufficient for eyeblink conditioning in rats in the present study, suggesting that the necessary visual CS pathway for cerebellar learning may be primarily unilateral. Unilateral CS input has been demonstrated for the auditory CS pathway in rats, where the inputs to the PN that are necessary for eyeblink conditioning arise from the inferior colliculus and medial auditory thalamus in the hemisphere contralateral to the conditioned eye (Halverson and Freeman 2006; Campolattaro et al. 2007; Halverson et al. 2008). Inactivation or lesion studies are needed to determine whether the visual CS pathway for eyeblink conditioning is unilateral.

Rats in the paired groups in Experiments 1-3 showed substantial savings when switched from the stimulation CS to a light. Experiments using stimulation of the mossy fiber inputs into the cerebellum including the $\mathrm{PN}$ and middle cerebellar peduncle (MCP) as a CS during eyeblink conditioning demonstrated very rapid CR acquisition and complete transfer of CRs from stimulation to a tone CS in a few rabbits and from forepaw stimulation to MCP stimulation in ferrets (Steinmetz et al. 1986; Steinmetz 1990; Tracy et al. 1998; Hesslow et al. 1999; Freeman Jr. and Rabinak 2004). Stimulation of the PN and MCP likely activated a large number of mossy fibers corresponding to many different CS inputs. Activation of a large number of mossy fibers should increase the rate of CR acquisition and make transfer of CRs from a stimulation CS to a peripheral CS more likely. Experiments 1-3 used stimulation of visual structures that have a direct projection to the PN, thus activating mossy fibers associated with only that particular CS input. However, the rate of acquisition using stimulation of visual areas was slower than acquisition using PN stimulation (Freeman Jr. and Rabinak 2004). Slower CR acquisition, relative to the rate observed with $\mathrm{PN}$ stimulation, is likely due to fewer mossy fibers being activated by stimulating upstream of the PN. The lack of complete CR transfer from a LGN, SC, or VCTX stimulation CS in phase 1 to a light CS in phase 2 provides additional evidence that the visual CS pathway for eyeblink conditioning is comprised of parallel inputs to the PN. Stimulation of each structure supported the same level of savings in phase 2 , indicating that a portion of the mossy fibers engaged during conditioning with a light CS was activated by the stimulation CS in phase 1. Perhaps complete transfer of eyeblink CRs would be observed to the light CS in phase 2 if all three areas were stimulated simultaneously during phase 1 .

Stimulation of the VCTX was a sufficient CS for eyeblink conditioning in this study, presumably by activating the direct projection to the PN (Glickstein et al. 1972; Baker et al. 1976; Mower et al. 1980). However, lesions of the visual cortex in rabbits do not prevent CR acquisition with a light CS (Koutalidis et al. 1988). Removal of the VCTX also does not prevent retention of eyeblink CRs to a light CS in dogs and monkeys (Hilgard and Marquis 1935, 1936). Moreover, decortication does not prevent acquisition or retention of eyeblink conditioning with light or tone CSs in rabbits (Oakley and Russell 1972, 1977). Lesions of the visual cortex also do not prevent acquisition, expression, or extinction of fear-potentiated startle using a light CS in rats (Falls and Davis 1993). These results provide evidence that the VCTX is not necessary for acquisition or retention of simple Pavlovian conditioning, but may provide parallel visual input along with other visual structures that is collectively sufficient to support conditioning. Further investigation is needed to determine the particular role of the visual cortex in eyeblink conditioning with a visual CS.

The SC has direct inputs to the PN from the superficial, intermediate, and deep layers (Kawamura and Brodal 1973; Graham 1977; Holstege and Collewijn 1982; Wells et al. 1989). Stimulation of this pathway supported eyeblink conditioning in the present study. However, large bilateral lesions of the SC alone did not prevent acquisition of eyeblink conditioning or fear-potentiated startle to a visual CS (Tischler and Davis 1983; Koutalidis et al. 1988; Meloni and Davis 1999; Waddell et al. 2003). Thus, as with the VCTX, the SC is not necessary for conditioning with a visual $\mathrm{CS}$, but may provide a parallel visual input to the PN that combines with other visual structures to support cerebellar learning.

The ventral LGN also has a direct unilateral projection to the PN (Graybiel 1974; Ribak and Peters 1975; Wells et al. 1989; Moore et al. 2000). The dorsal LGN primarily projects to the VCTX (Kawano 1998), and VCTX projects to PN (Baker et al. 1976; Mower et al. 1980), which could comprise a thalamo-cortical-pontine component of the visual CS pathway. The cerebellar (interpositus nucleus) feedback projection to the ventral LGN (Zimny et al. 1986) may increase activity in the LGN to the light CS used in training during acquisition of eyeblink conditioning. Increased activity through cerebellar feedback in the LGN could enhance light CS input to the PN and the corresponding PN input into the cerebellum, thus strengthening learning. The enhancement of activity in visual areas due to cerebellar feedback could be a neural mechanism corresponding to increased CS processing during Pavlovian conditioning (Mackintosh 1975).

The results of the present experiments provide additional evidence for the hypothesis that the visual CS pathway for eyeblink conditioning is composed of parallel PN inputs from LGN, SC, and VCTX (Fig. 5; Koutalidis et al. 1988). Lesion studies have provided evidence that any one of the areas in the visual CS pathway is capable of supporting acquisition and retention of visual CRs. An unanswered question is whether the ventral LGN plays a more significant role in light conditioning compared to the other structures in the pathway through its anatomical connections with the PN and cerebellum. 


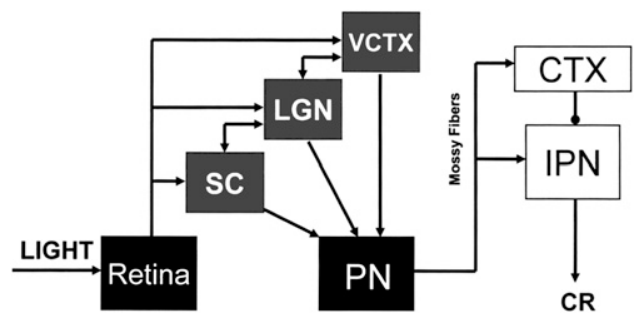

Figure 5. Hypothesized visual CS pathway for delay eyeblink conditioning. Visual information is projected directly from the retina to the (SC) superior colliculus, (LGN) lateral geniculate nucleus, and (VCTX) visual cortex. There are also connections between the SC, LGN, and VCTX. Visual information is conveyed through direct projections to the (PN) pontine nuclei from the SC, LGN, and VCTX. The PN sends mossy fiber projections into the cerebellum that synapse onto granule cells in the (CTX) cerebellar cortex and neurons in the (IPN) interpositus nucleus. Finally, the IPN sends the output for CR expression.

\section{Materials and Methods}

\section{Subjects}

Subjects were 62 male Long-Evans rats that were 250-300 g at the beginning of the experiment. The rats were housed in the animal colony within Spence Laboratories of Psychology at The University of Iowa (Iowa City, IA). Rats were given ad libitum access to food and water and were maintained on a 12-h light/dark cycle with light onset at 7:00 a.m.

\section{Surgery}

One week before training, rats were removed from their home cages and anesthetized with isoflurane. After the onset of anesthesia, the rats were fitted with differential electromyography (EMG) electrodes (stainless steel) that were implanted into the upper-left orbicularis oculi muscle. The reference electrode was a silver wire attached to a stainless steel skull screw. The EMG electrode leads terminated in gold pins in a plastic connecter. A bipolar stimulating electrode (Plastics One) for delivering the shock US was implanted subdermally caudal to the left eye. An additional bipolar stimulating electrode was implanted into the right LGN, right SC, or right VCTX. The stereotaxic coordinates taken from bregma for the LGN were $4.5 \mathrm{~mm}$ posterior, $4.3 \mathrm{~mm}$ lateral, and $6.2 \mathrm{~mm}$ ventral to the skull surface. Stereotaxic coordinates taken from bregma for the SC were $6.0 \mathrm{~mm}$ posterior, $1.4 \mathrm{~mm}$ lateral, and $3.8 \mathrm{~mm}$ ventral to the skull surface. Stereotaxic coordinates taken from bregma for the VCTX were $7.9 \mathrm{~mm}$ posterior, $3.4 \mathrm{~mm}$ lateral, and $1.5 \mathrm{~mm}$ ventral to the skull surface. The plastic connector housing the EMG electrode leads, both bipolar stimulating electrodes, and three skull screws were secured to the skull surface with Osteobond copolymer bone cement (Zimmer). Rats were maintained on 3.0\% Sulfatrim (Hi-Tech Pharmacal Co.) in water for $4 \mathrm{~d}$ after surgery.

\section{Apparatus}

The apparatus has been described in detail previously (Campolattaro et al. 2007; Halverson et al. 2008). The conditioning apparatus consisted of two small-animal sound-attenuating chambers (BRS/ LVE). The back wall of the sound-attenuating chamber was fitted with a $4 \mathrm{~W}$ CS light, which produced a white-light whole-field illumination. Eyelid EMG activity was amplified differentially (gain, 2000), filtered (500-5000 Hz), and integrated (time constant, $20 \mathrm{msec}$ ).

\section{Stimulation procedure}

Electrical stimulation of the various structures in the visual system functioned as the CS in the initial phase of each experiment. Stimulation consisted of a $200-\mathrm{Hz}$ train of 0.1 -msec biphasic pulses for $300 \mathrm{msec}$. The stimulation intensity for the CS was set before training by setting the stimulating current to elicit an observable behavioral response and then decreasing the current in $5-\mu \mathrm{A}$ increments until no movement was detected (Campolattaro et al. 2007). Observed movements included, but were not limited to, rearing responses, head movements, and cessation of movement. The stimulation threshold for LGN and SC stimulation was between 50 and $150 \mu \mathrm{A}$. The stimulation threshold for VCTX stimulation was between 180 and $250 \mu \mathrm{A}$. A pilot study indicated that a lower stimulation threshold in the VCTX did not support eyeblink conditioning.

\section{Conditioning procedure}

The rats were allowed to adapt to the training environment for 5 min before each training session. Rats were then given five sessions of either paired or explicitly unpaired eyeblink conditioning with a 300-msec stimulation CS and 25-msec periorbital shock US. Paired training sessions consisted of 100 trials, 90 trials were paired with the US, and every tenth trial was a CS-alone trial. The CS-alone trials were included in order to assess CRs that are uncontaminated by the UR. The interstimulus interval (ISI) for the paired trials was $275 \mathrm{msec}$. Trials were separated by an intertrial interval (ITI) that averaged $30 \mathrm{sec}$. Unpaired training consisted of 200 trial sessions consisting of 100 trials of the CS explicitly unpaired with 100 trials of the US used in paired training. The ITI averaged $15 \mathrm{msec}$ to match the total time spent in the conditioning chamber and the temporal distribution of CS and US presentations with the paired groups. All rats were then given three sessions of paired conditioning with a $4 \mathrm{~W}, 300-\mathrm{msec}$, white-light $\mathrm{CS}$ and the same periorbital shock US from the first phase of training. The intensity of the shock US was set at two times threshold for eliciting a discrete eyeblink (range of final current intensity, 2-5 mA; $60 \mathrm{~Hz}$; constant current). The US intensity was set before the first session and was not changed during the rest of the experiment. Parameters of the paired sessions with the light CS matched the ISI and ITI of the paired sessions with the stimulation CS in the first phase of training.

\section{Histology}

After training, the rats were euthanized with a lethal injection of sodium pentobarbital $(150 \mathrm{mg} / \mathrm{kg})$ and transcardially perfused with $\sim 100 \mathrm{~mL}$ of physiological saline followed by $\sim 300 \mathrm{~mL}$ of $10 \%$ buffered formalin. After perfusion, the brains were post-fixed in the same fixative for a minimum of $24 \mathrm{~h}$, cryo-protected in a 30\% sucrose in formalin solution, and subsequently sectioned at $50 \mu \mathrm{m}$ with a sliding microtome. Electrode placements were then verified using a light microscope and a stereotaxic brain atlas (Paxinos and Watson 1998).

\section{Acknowledgment}

This research was supported by National Institute for Mental Health grant MH080005 to J.H.F.

\section{References}

Alonso, J.M., Usrey, W.M., and Reid, R.C. 2001. Rules of connectivity between geniculate cells and simple cells in cat primary visual cortex. $J$. Neurosci. 21: 4002-4015.

Attwell, P.J., Rahman, S., Ivarsson, M., and Yeo, C.H. 1999. Cerebellar cortical AMPA-kainate receptor blockade prevents performance of classically conditioned nictitating membrane responses. J. Neurosci. 19: RC45:1-RC45:6.

Attwell, P.J., Rahman, S., and Yeo, C.H. 2001. Acquisition of eyeblink conditioning is critically dependent on normal function in cerebellar cortical lobule HVI. J. Neurosci. 21: 5715-5722.

Baker, J., Gibson, A., Glickstein, M., and Stein, J. 1976. Visual cells in the pontine nuclei of the cat. J. Physiol. 255: 415-433.

Bloedel, J.R. and Courville, L. 1981. Cerebellar afferent systems. In Handbook of physiology, Section I: The nervous system (eds. J.M. Brookhart et al.), Vol. II, pp. 735-830. Williams and Wilkins, Baltimore, MD.

Brodal, A. 1981. Neurological anatomy. Oxford University Press, New York. Campolattaro, M.M., Halverson, H.E., and Freeman, J.H. 2007. Medial auditory thalamic stimulation as a conditioned stimulus for eyeblink conditioning in rats. Learn. Mem. 14: 152-159. 
Espinoza, S.G. 1983. Single unit studies in the visual cortex of rodents. Arch. Biol. Med. Exp. (Santiago) 16: 305-315.

Falls, W.A. and Davis, M. 1993. Visual cortex ablations do not prevent extinction of fear-potentiated startle using a visual conditioned stimulus. Behav. Neural Biol. 60: 259-270.

Fleming, M.D., Benca, R.M., and Behan, M. 2006. Retinal projections to the subcortical visual system in congenic albino and pigmented rats. Neuroscience 143: 895-904.

Freeman Jr., and Rabinak, C.A. 2004. Eyeblink conditioning in rats using pontine stimulation as a conditioned stimulus. Integr. Physiol. Behav. Sci. 39: 180-191.

Freeman Jr., J.H., Halverson, H.E., and Poremba, A. 2005. Differential effects of cerebellar inactivation on eyeblink conditioned excitation and inhibition. J. Neurosci. 25: 889-895.

Freeman, J.H., Halverson, H.E., and Hubbard, E.M. 2007. Inferior colliculus lesions impair eyeblink conditioning in rats. Learn. Mem. 14: 842-846.

Glickstein, M., Stein, J., and King, R.A. 1972. Visual input to the pontine nuclei. Science 178: 1110-1111.

Glickstein, M., Cohen, J.L., Dixon, B., Gibson, A., Hollins, M., Labossiere, E., and Robinson, F. 1980. Corticopontine visual projections in macaque monkeys. J. Comp. Neurol. 190: 209-229.

Gonzalo-Ruiz, A. and Leichnetz, G.R. 1987. Collateralization of cerebellar efferent projections to the paraoculomotor region, superior colliculus, and medial pontine reticular formation in the rat: A fluorescent doublelabeling study. Exp. Brain Res. 68: 365-378.

Gormezano, I., Schneiderman, N., Deaux, E., and Fuentes, I. 1962 Nictitating membrane: Classical conditioning and extinction in the albino rabbit. Science 138: 33-34.

Graham, J. 1977. An autoradiographic study of the efferent connections of the superior colliculus in the cat. J. Comp. Neurol. 173: 629-654.

Graybiel, A.M. 1974. Visuo-cerebellar and cerebello-visual connections involving the ventral lateral geniculate nucleus. Exp. Brain Res. 20: 303-306.

Halverson, H.E. and Freeman, J.H. 2006. Medial auditory thalamic nuclei are necessary for eyeblink conditioning. Behav. Neurosci. 120: 880-887.

Halverson, H.E., Poremba, A., and Freeman, J.H. 2008. Medial auditory thalamus inactivation prevents acquisition and retention of eyeblink conditioning. Learn. Mem 15: 532-538.

Hesslow, G., Svensson, P., and Ivarsson, M. 1999. Learned movements elicited by direct stimulation of cerebellar mossy fiber afferents. Neuron 24: $179-185$.

Hilgard, E.R. and Marquis, D.G. 1935. Acquisition, extinction, and retention of conditioned lid responses to light in dogs. J. Comp. Psychol. 19: $29-58$.

Hilgard, E.R. and Marquis, D.G. 1936. Conditioned eyelid responses in monkeys, with a comparison of dog, monkey, and man. Psychol. Monogr. 47: 186-198.

Holstege, G. and Collewijn, H. 1982. The efferent connections of the nucleus of the optic tract and the superior colliculus in the rabbit. $J$. Comp. Neurol. 209: 139-175.

Kawamura, K. and Brodal, A. 1973. The tectopontine projection in the cat: An experimental anatomical study with comments on pathways for teleceptive impulses to the cerebellum. J. Comp. Neurol. 149: 371-390.

Kawano, J. 1998. Cortical projections of the parvocellular laminae C of the dorsal lateral geniculate nucleus in the cat: An anterograde wheat germ agglutinin conjugated to horseradish peroxidase study. J. Comp. Neurol. 392: $439-457$.

Knowlton, B.J., Thompson, J.K., and Thompson, R.F. 1993. Projections from the auditory cortex to the pontine nuclei in the rabbit. Behav. Brain Res. 56: 23-30.

Kolmac, C. and Mitrofanis, J. 2000. Organization of brain stem afferents to the ventral lateral geniculate nucleus of rats. Vis. Neurosci. 17: 313-318.

Koutalidis, O., Foster, A., and Weisz, D.J. 1988. Parallel pathways can conduct visual CS information during classical conditioning of the NM response. J. Neurosci. 8: 417-427.

Krupa, D.J. and Thompson, R.F. 1997. Reversible inactivation of the cerebellar interpositus nucleus completely prevents acquisition of the classically conditioned eyeblink response. Learn. Mem. 3: 545-556.

Lashley, K.S. 1934. The mechanism of vision. VIII. The projection of the retina upon the cerebral cortex of the rat. J. Comp. Neurol. 60: 57-79.

Lavond, D.G., Hembree, T.L., and Thompson, R.F. 1985. Effect of kainic acid lesions of the cerebellar interpositus nucleus on eyelid conditioning in the rabbit. Brain Res. 326: 179-182.

Mackintosh, N.J. 1975. A theory of attention: Variations in the associability of stimuli with reinforcement. Psychol. Rev. 82: 276-298.

Major, D.E., Rodman, H.R., Libedinsky, C., and Karten, H.J. 2003. Pattern of retinal projections in the California ground squirrel (Spermophilus beecheyi): Anterograde tracing study using cholera toxin. J. Comp. Neurol. 463: 317-340.
Matteau, I., Boire, D., and Ptito, M. 2003. Retinal projections in the cat: A cholera toxin B subunit study. Vis. Neurosci. 20: 481-493.

McCormick, D.A. and Thompson, R.F. 1984. Cerebellum: Essential involvement in the classically conditioned eyelid response. Science 223: 296-299.

Medina, J.F., Nores, W.L., Ohyama, T., and Mauk, M.D. 2000. Mechanisms of cerebellar learning suggested by eyelid conditioning. Curr. Opin. Neurobiol. 10: 717-724.

Meloni, E.G. and Davis, M. 1999. Muscimol in the deep layers of the superior colliculus/mesencephalic reticular formation blocks expression but not acquisition of fear-potentiated startle in rats. Behav. Neurosci. 113: $1152-1160$

Moore, R.Y., Weis, R., and Moga, M.M. 2000. Efferent projections of the intergeniculate leaflet and the ventral lateral geniculate nucleus in the rat. J. Comp. Neurol. 420: 398-418.

Mower, G., Gibson, A., Robinson, F., Stein, J., and Glickstein, M. 1980. Visual pontocerebellar projections in the cat. J. Neurophysiol. 43: 355-366.

Nolan, B.C. and Freeman Jr., J.H. 2005. Purkinje cell loss by OX7-saporin impairs excitatory and inhibitory eyeblink conditioning. Behav. Neurosci. 119: 190-201.

Nolan, B.C. and Freeman, J.H. 2006. Purkinje cell loss by OX7-saporin impairs acquisition and extinction of eyeblink conditioning. Learn. Mem. 13: 359-365.

Oakley, D.A. and Russell, I.S. 1972. Neocortical lesions and Pavlovian conditioning. Physiol. Behav. 8: 915-926.

Oakley, D.A. and Russell, I.S. 1977. Subcortical storage of Pavlovian conditioning in the rabbit. Physiol. Behav. 18: 931-937.

Ohyama, T., Nores, W.L., Medina, J.F., Riusech, F.A., and Mauk, M.D. 2006 Learning-induced plasticity in deep cerebellar nucleus. J. Neurosci. 26: 12656-12663

Paxinos, G. and Watson, C. 1998. The rat brain in stereotaxic coordinates. Academic Press, New York.

Perrett, S.P. and Mauk, M.D. 1995. Extinction of conditioned eyelid responses requires the anterior lobe of cerebellar cortex. J. Neurosci. 15: 2074-2080.

Perrett, S.P., Ruiz, B.P., and Mauk, M.D. 1993. Cerebellar cortex lesions disrupt learning-dependent timing of conditioned eyelid responses. J. Neurosci. 13: 1708-1718.

Prichard, J.R., Armacanqui, H.S., Benca, R.M., and Behan, M. 2007. Lightdependent retinal innervation of the rat superior colliculus. Anat. Rec. (Hoboken) 290: 341-348.

Redgrave, P., Mitchell, I.J., and Dean, P. 1987. Descending projections from the superior colliculus in rat: A study using orthograde transport of wheatgerm-agglutinin conjugated horseradish peroxidase. Exp. Brain Res. 68: 147-167.

Ribak, C.E. and Peters, A. 1975. An autoradiographic study of the projections from the lateral geniculate body of the rat. Brain Res. 92: $341-368$.

Rosen, D.J., Steinmetz, J.E., and Thompson, R.F. 1989. Classical discrimination conditioning of the rabbit's eyelid response using pontine stimulation as a conditioned stimulus. Behav. Neural Biol. 52: 51-62.

Schmahmann, J.D. and Pandya, D.N. 1989. Anatomical investigation of projections to the basis pontis from posterior parietal association cortices in rhesus monkey. J. Comp. Neurol. 289: 53-73.

Schneiderman, N., Fuentes, I., and Gormezano, I. 1962. Acquisition and extinction of the classically conditioned eyelid response in the albino rabbit. Science 136: 650-652.

Steinmetz, J.E. 1990. Classical nictitating membrane conditioning in rabbits with varying interstimulus intervals and direct activation of cerebellar mossy fibers as the CS. Behav. Brain Res. 38: 97-108.

Steinmetz, J.E. and Sengelaub, D.R. 1992. Possible conditioned stimulus pathway for classical eyelid conditioning in rabbits. I. Anatomical evidence for direct projections from the pontine nuclei to the cerebellar interpositus nucleus. Behav. Neural Biol. 57: 103-115.

Steinmetz, J.E., Rosen, D.J., Chapman, P.F., Lavond, D.G., and Thompson, R.F. 1986. Classical conditioning of the rabbit eyelid response with a mossy fiber stimulation CS. I. Pontine nuclei and middle cerebellar peduncle stimulation. Behav. Neurosci. 100: 871-880.

Steinmetz, J.E., Logan, C.G., Rosen, D.J., Thompson, J.K., Lavond, D.G., and Thompson, R.F. 1987. Initial localization of the acoustic conditioned stimulus projection system to the cerebellum essential for classical eyelid conditioning. Proc. Natl. Acad. Sci. 84: 3531-3535.

Steinmetz, J.E., Lavond, D.G., and Thompson, R.F. 1989. Classical conditioning in rabbits using pontine nucleus stimulation as a conditioned stimulus and inferior olive stimulation as a unconditioned stimulus. Synapse 3: 225-233.

Thompson, R.F. 2005. In search of memory traces. Annu. Rev. Psychol. 56: 1-23.

Tischler, M.D. and Davis, M. 1983. A visual pathway that mediated fearconditioned enhancement of acoustic startle. Brain Res. 276: 55-71.

Tracy, J.A., Thompson, J.K., Krupa, D.J., and Thompson, R.F. 1998. Evidence of plasticity in the pontocerebellar conditioned stimulus pathway 
during classical conditioning of the eyeblink response in the rabbit. Behav. Neurosci. 112: 267-285.

Waddell, J., Heldt, S., and Falls, W.A. 2003. Post-training lesion of the superior colliculus interferes with feature-negative discrimination of fear-potentiated startle. Behav. Brain Res. 142: 115-124.

Watanabe, T., Michaelis, T., and Frahm, J. 2001. Mapping of retinal projections in the living rat using high-resolution 3D gradientecho MRI with $\mathrm{Mn}^{2+}$-induced contrast. Magn. Reson. Med. 46: 424429.

Weber, J.T. and Harting, J.K. 1980. The efferent projections of the pretectal complex: An autoradiographic and horseradish peroxidase analysis. Brain Res. 194: 1-28.
Wells, G.R., Hardiman, M.J., and Yeo, C.H. 1989. Visual projections to the pontine nuclei in the rabbit: Orthograde and retrograde tracing studies with WGA-HRP. J. Comp. Neurol. 279: 629-652.

Zimny, R., Grottel, K., and Kotecki, A. 1986. Evidence for cerebellar efferents to the ventral lateral geniculate nucleus and the lateral terminal nucleus of the accessory optic system in the rabbit. A morphological study with comments on the organization features of visuo-oculomotor-trunco-cerebellar loops. J. Hirnforsch. 27: 159-212.

Received January 13, 2009; accepted in revised form March 18, 2009. 


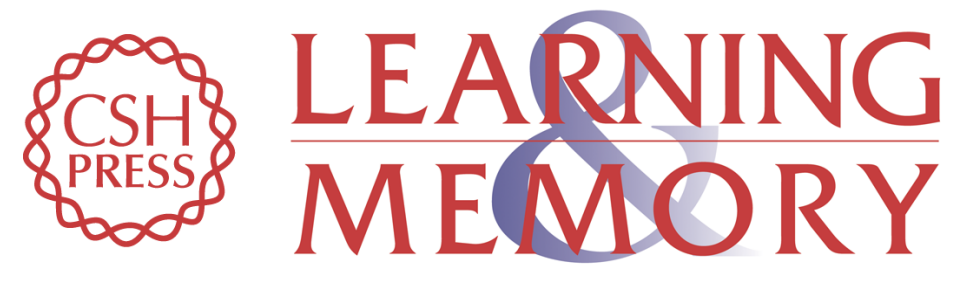

\section{Stimulation of the lateral geniculate, superior colliculus, or visual cortex is sufficient for eyeblink conditioning in rats}

Hunter E. Halverson, Erin M. Hubbard and John H. Freeman

Learn. Mem. 2009, 16:

Access the most recent version at doi:10.1101//m.1340909

References This article cites 65 articles, 17 of which can be accessed free at:

http://learnmem.cshlp.org/content/16/5/300.full.html\#ref-list-1

License

Email Alerting Receive free email alerts when new articles cite this article - sign up in the box at the Service top right corner of the article or click here. 